\title{
LA ESCRITURA DRAMÁTICA COLOMBIANA DEL SIGLO XXI
}

THE DRAMATIC WRITING OF COLOMBIA

IN THE TWENTY-FIRST CENTURY

\section{Alexandra Aguirre Rojas Mario Henao}

Universidad Nacional de Colombia

Bogotá - Colômbia

\begin{abstract}
The aim of this article is to provide an outline of contemporary theatre writing in Colombia by studying six representative dramatic works. An abandonment of Classical Theatre structures and the reinvention after the predominance of Collective Creation until the late 80 s define these artistic expressions. Thus, a register of emerging authors' voices are set apart from previous didactic strategies, giving rise to playwriting that focuses mainly on the individual view. Similarly, in this work we analyse the transformation of the visions over the phenomenon of violence, which has traditionally been central to Colombian playwrights.
\end{abstract}

Keywords: Contemporary theater, Colombia, violence, history.

\section{Resumen}

Este artículo se dedica a estudiar seis obras dramáticas con el fin de trazar un panorama sobre la escritura teatral colombiana contemporánea. Vemos cómo el teatro ha abandonado la estructura clásica y se ha reinventado después de la primacía que tuvo el teatro colectivo hasta la década del 80 del siglo pasado. Así, hay un registro de nuevas voces autorales que se separan de la estrategia del teatro de índole didáctica para dar paso a una escritura que hace énfasis en una mirada individual. Del mismo modo, este trabajo se ocupa en revisar cómo se ha transformado la mirada del teatro colombiano sobre el fenómeno de la violencia, que ha sido históricamente el tema del que más se han ocupado los dramaturgos colombianos.

Palabras claves: Teatro contemporáneo, Colombia, violencia, historia.

\section{Resumo}

Neste artigo se estudam seis obras dramáticas, tentando traçar um panorama da escrita teatral colombiana contemporânea. Analisamos como o teatro abandona a estrutura clássica e se reinventa depois da primazia que teve o teatro coletivo até a década de 80 do século passado. Verifica-se assim o registro de novas vozes autorais, que se separam das estratégias do teatro de índole didática para dar passo a uma escrita que enfatiza o individual. Da mesma maneira, no trabalho fazemos uma revisão de como se foi transformando o olhar do teatro colombiano sobre o fenómeno da violência, um tema que tem sido historicamente privilegiado pelos dramaturgos colombianos.

Palavras-chave: Teatro contemporâneo, Colômbia, violência, história. 
En el año 2013, el Ministerio de Cultura de Colombia publicó, en colaboración con la revista mexicana Paso de gato, una antología en dos tomos titulada Dramaturgia colombiana contemporánea (LAMUS, 2013). Esta publicación puede entenderse como un diagnóstico del estado de la dramaturgia en Colombia. La selección fue hecha por una de las investigadoras teatrales más importantes del país, Marina Lamus Obregón, quien eligió a una serie de autores que aparentemente representan lo mejor de la producción dramática contemporánea. Esta antología marca una etapa en el proceso de desarrollo del texto dramático en Colombia, pues expone a un grupo de dramaturgos, cuja obra es ejemplo de las formas que ha tomado ese texto y de las nuevas manifestaciones dentro de la dramaturgia colombiana de la primera década del siglo XXI. No obstante, lo anterior puede ser cuestionado, ya que surge la pregunta de si los textos seleccionados dan cuenta de ese desarrollo o si, por el contrario, son solo una selección que no alcanza una unidad y que tampoco ofrece una mirada novedosa.

La antología de Marina Lamus marca el final de un periodo que tiene como inicio el Taller Nacional de Dramaturgia, en 1996. Este taller fue una escuela en la que participaron varios de los autores que alcanzaron un lugar importante en la primera década del siglo XXI. Además, inaugura una forma de participación en la dramaturgia basada en los laboratorios de escritura, los talleres y las escuelas de formación. Muchos de los autores contemporáneos participaron de estas escuelas, que influenciaron sus poéticas y que además permitieron poner en contacto sus preocupaciones dramáticas con las de autores reconocidos de países latinoamericanos como Mauricio Kartún y Rafael Spregelburd (de Argentina), Marco Antonio de la Parra (de Chile), entre otros. El periodo que comprenderá este artículo empieza al final de la década del noventa del siglo XX hasta la primera década del XXI, tiempo en el cual se crea una red de trabajo entre autores, directores y grupos que permite una mayor producción de textos dramáticos. Es necesario reconocer la influencia que tuvo la participación de escritores reconocidos en Latinoamérica en la generación más joven y lo importante que fue para los autores colombianos de más tradición compartir sus experiencias con sus colegas extranjeros.

No es la primera vez que una influencia extranjera afecta el teatro colombiano. La llegada del actor y director japonés Seki Sano en los años cincuenta desembocó en el desarrollo del teatro de la Candelaria. Ese grupo se convirtió en un referente en el teatro latinoamericano, pues desarrolló el método de creación colectiva, que implicó una concepción del teatro diferente a la tradicional, ya no basada en un texto escrito por un autor, sino en una creación simultánea de texto y puesta, en la que participaban todos los integrantes del grupo. Seki Sano llegó al país para desarrollar un proyecto actoral que le brindó a los actores y dramaturgos colombianos una nueva 
perspectiva sobre el teatro, basada no solamente en la tradicional teoría de Konstantin Stanislavski, sino en las del otro teórico y director ruso, Vsévolod Meyerhold.

Ya la influencia extranjera que ocurrió a finales del siglo XX impactó, desde una perspectiva escrita, el desarrollo de textos dramáticos. Se trata de una confluencia de situaciones, de la necesidad de una escritura individual y de la formación y apertura de espacios en los que se ejercita esa escritura. Si hasta hace unos años la dramaturgia colombiana se desarrollaba por medio del método de la creación colectiva, en la actualidad ha habido una vuelta al texto y a la figura del autor, que es en parte producto de esas mayores posibilidades de formación. De cierta manera, la reflexión sobre el país pareció requerir una mirada individual de los dramaturgos, ya que a lo que se dirigió la atención fue a la experiencia personal, a una mirada desde la cual se interpreta una serie de temas. Esa mirada ya no tiene como intención la generación de un relato colectivo, sino la acentuación de la perspectiva que depende del sujeto y su vivencia. Esto no significa que la creación colectiva haya desaparecido, solo que empezó a compartir el escenario con autores nuevos.

Entrando en la primera década del siglo XXI se pudieron ver los resultados de las diferentes escuelas de formación. Muchos autores viajaron al extranjero a formarse, con becas y otros apoyos, y a su regreso empezaron a conformar una actividad teatral más completa, en la que la dramaturgia y la puesta en escena se tenían en cuenta. Esto generó que en la última década del siglo XX se formaran las redes de integrantes del campo teatral (dramaturgos, actores, directores, entre otros), que se consolidaron en la primera década de este siglo y que construyeron un campo de mayor acción para el teatro. Se fortalecen las alianzas entre teatros, grupos y autores, surgiendo nuevos espacios de puesta en escena; los grupos ya no se entienden solo como unidades cerradas, sino como formas de gestión teatral, es decir, como agrupaciones que distribuyen tareas más allá de lo específicamente estético. Ya no se trata de un grupo estático, sino de una reunión de personas alrededor de un proyecto, y para esto, estas agrupaciones gestionan recursos, crean alianzas con otros sectores (públicos y privados), organizan encuentros, festivales, talleres, laboratorios y toda una serie de actividades que mantienen en desarrollo el escenario teatral. Y, sumado a eso, las dramaturgias se transforman. Por ejemplo, la fragmentación dramática, aquella que permitió que la dramaturgia no necesitara de una historia lineal, que rompió con la estructuración tradicional de una historia en escenas y actos, y con ello logró que el texto estuviera pensado desde su componente escénico, es decir, que funcionara como provocador de acciones más que como un guión, y que fue tan importante en la primera mitad del siglo XX, abre el camino a otras formas de fragmentación que posibilitan diferentes perspectivas de la realidad y su reconstrucción. No se 
trata ahora, para los dramaturgos más jóvenes, de romper con las unidades tradicionales del teatro (espacio, acción y tiempo), sino que el personaje mismo se fragmenta y con ello las maneras de dar cuenta de la realidad, que es siempre una interpretación, una perspectiva que hace que las acciones sean solo una proyección del personaje que también empieza a estar obligado a narrar sus propias acciones.

$\mathrm{Al}$ mismo tiempo que aparecen más opciones de poner en escena las obras, el texto dramático vuelve a hacer de lo literario lo central. En la creación colectiva el elemento literario se había desplazado y compartía un espacio con otros aspectos escénicos, ya que implicaba un trabajo de grupo en la creación. Sin embargo, ahora es un dramaturgo el encargado de la creación, y realiza una actividad literaria, aunque trata de mantener un equilibrio con lo escénico. Además de esto, los temas que preocupan a los autores se han diversificado. La violencia y el conflicto que ha afectado a Colombia desde hace más de cincuenta años siguen teniendo una presencia importante, pero ya no se trata solo de la denuncia o de la pertenencia ideológica a alguno de los participantes en ese conflicto (la guerrilla, los paramilitares o el gobierno).

Los colombianos compartimos un escenario de guerra desde hace muchas décadas, y aunque se han dado cambios, la situación de conflicto se mantiene, lo que hace que la escritura y las formas de expresión remitan y sean influenciadas por esa situación. No solo el conflicto se ha hecho cotidiano, sino que ha quedado como un fondo que esporádicamente recuerda su presencia. Los conflictos urbanos toman cierto protagonismo y hay una intención de hacer de la cotidianidad el lugar de reflexión dramática. A esto hay que agregar los intentos por hacer de la realidad una forma de experiencia simbólica que se construye o con la tradición indígena o con las herramientas de la industria cultural.

No obstante lo anterior, no hay que pecar de optimismo y reconocer que se está aún en un momento de formación de los agentes del teatro, tanto de los dramaturgos, actores, directores y productores, como del público y de los críticos. La antología publicada por el Ministerio de Cultura es un ejemplo de ello, pues a pesar de tener en cuenta grandes autores, no selecciona a otros que están consolidando una dramaturgia original y arriesgada. Seguimos en un momento de experimentación y de reorganización de los agentes del teatro, existe una fuerte intención de generación dramática y uno de los intereses de este artículo es exponer una muestra de esas propuestas que son parte de la dinámica del campo teatral. Para esto se propone hacer un análisis de la antología y de algunas ausencias que hay en ella. 
Marina Lamus Obregón divide la antología en dos tomos, según las edades de los autores. Esta división puede dar a entender una diferenciación generacional. La primera parte reúne a autores que están entre los 52 y los 67 ańos. En apariencia, este grupo corresponde a aquellos autores que consolidaron su dramaturgia a finales del siglo y que aún se mantienen activos. La segunda parte de la antología está integrada por autores más jóvenes que nacieron después de la década del setenta del siglo XX, a excepción de Ana María Vallejo, quien nació en 1965 y que fácilmente podría ser ubicada en el primer tomo de la antología. Esta división generacional expone también las diferencias entre las concepciones estéticas y dramáticas de los autores, que es también un criterio que los ubica en uno y otro tomo, aunque esta división estética y poética no está justificada de forma específica en el libro. Ejemplo de esto es el caso de Ana María Vallejo, pues su obra, Oraciones, parece estar más en consonancia con la concepción estética de la primera parte. En este punto habría que aclarar que en la antología lo que se relaciona es una serie de obras, de textos dramáticos, no de poéticas de los autores.

El primer tomo de la antología reúne diez obras: Solo como de un sueño de pronto nos levantamos de Beatriz Camargo Estrada; Carruaje de viejos con látigo verde de Henry Díaz Vargas; El solar de los mangos de Orlando Cajamarca Castro; Tribulaciones de un autor desconcertado, o la saga del espejo constante de José Assad Cuéllar; La técnica del hombre blanco de Víctor Viviescas; Ortaet (Proyecto imposible) de Sandro Romero Rey; Donde se descomponen las colas de los burros de Carolina Vivas Ferreira; La procesión va por dentro de José Domingo Garzón; Sara dice de Fabio Rubiano Orjuela y Pequeñas traiciones. A modo de drama satírico de Rodrigo Rodríguez. Para el análisis que se va a desarrollar en este artículo se seleccionaron tres, las de Orlando Cajamarca, Víctor Viviescas y José Domingo Garzón ${ }^{1}$. Esta selección se basa en cierto grado de representatividad que estas tres obras tienen, al evidenciar rasgos que son comunes al resto de las obras antologadas. Las tres comparten aspectos formales y de contenido, al tiempo que expresan particularidades en la forma de construir y comprender el texto dramático comunes a esa generación. El segundo tomo será analizado a partir de la obra de Felipe Vergara en relación con la de Fabio Rubiano, quien es un referente de la dramaturgia colombiana joven, y con Juan Camilo Ahumada, que no fue seleccionado por la autora, pero que es parte de las nuevas propuestas dramatúrgicas del país, con lo cual se dará un ejemplo de las ausencias que consideramos tiene la antología.

1 Fabio Rubiano será analizado de forma independiente en la segunda parte del artículo, motivo por el cual no se pone en relación de manera directa con los autores de este primer tomo, a pesar de ser uno de los dramaturgos más importantes de las últimas décadas. 
Una de las características que comparten las obras de la antología es la fragmentación de la unidad dramática tradicional. Frente a la estructura que organizaba el drama según escenas y actos en los que se desarrollaba una acción continua, se propone una serie de cuadros o planos con cierta independencia los unos de los otros. Esta fragmentación tiene como uno de sus resultados una insistente atención en el personaje, quien ya no se mueve dentro del espacio, como en una escena, sino que es una imagen inmóvil parlante que narra sus acciones y las de la obra, explica su estado actual, pero no ejecuta acciones concretas. Los personajes en estas piezas, más que actuar, hablan.

Esto es común en las tres piezas que se van a analizar en este apartado, pero se nota de manera particular en Elsolar de los mangos y en La procesión va por dentro. En la primera, la disposición del espacio escénico está hecha para concentrar la atención en los personajes que solo pueden relatar sus acciones. La indicación escénica dice: "Espacio dividido en tres planos contiguos: en el plano central, la Madre; en el lateral izquierdo, Ana; en el lateral derecho, Rosario" (CAJAMARCA, 2013, p. 77). Estas tres mujeres relatarán los hechos que las llevaron a la situación en la que se encuentran, lo que significa que la acción escenificada es la del discurso y que las acciones principales están fuera de la escena. La inmovilidad del personaje lo ubica en una situación comunicativa muy particular, pues no tiene interlocutor. Sus palabras son un continuo discurso sin destinatario y sin respuesta. En ese sentido, los diálogos desaparecen en esta pieza de Cajamarca, algo que también ocurre, de forma menos drástica, en las obras de Viviescas y Garzón. De esta manera, los elementos formales que ayudan a constituir el género dramático están ausentes. La acción es reducida a cero y los diálogos, ese procedimiento que permite el desarrollo de la acción y que permite la comunicación entre los personajes, son imposibles porque estos son estáticos y no tienen interlocutor, además están en una situación que no permite una transformación. Son personajes absolutamente solos, que ya nada pueden hacer para modificar su situación dramática. José Luis García-Barrientos (2012) afirma que solo puede considerarse acción lo que modifica una situación, por tal motivo el discurso expone una imposibilidad de transformación, pues esta ya ocurrió. En El solar de los mangos, solo al final se ejecuta una acción transformadora, la muerte de los personajes, pero esta acción no produce una nueva, sino que da fin a toda esperanza. Esta inmovilidad expone no solo la dificultad de transformación que tienen los personajes, sino que también da la sensación de que a pesar del paso del tiempo y de las aparentes modificaciones, el país, Colombia, sigue sumergido en las mismas dinámicas que impiden un cambio. Que los personajes estén estáticos declarando su discurso como única acción, señala que, al parecer, la palabra y el lamento son las únicas opciones y por lo mismo la razón de que no haya posibilidad de cambio. 
En La procesión va por dentro (GARZÓN, p. 2013) la inmovilidad de los personajes está dada por diferentes aspectos. En términos de contenido, la obra presenta a diferentes mujeres en diferentes momentos históricos. Todas están cerca de la muerte, habitaron la misma casa y se arrepienten de sus pecados. La motivación final de todas es aclarar sus vidas, por eso hacen sus testamentos y declaran el deseo de ser redimidas antes de morir. De esta forma, es posible reconocer un elemento similar al utilizado por Cajamarca: se trata del relato de la vida de los personajes. La obra no es la representación de las acciones, de lo que les ocurrió, sino la relación de hechos, todos sugeridos o latentes, que sucedieron en un pasado y fuera de escena. Además de esa característica, Garzón dispone la pieza en un espacio específico, una casa y sus cuartos, donde están las mujeres condenadas, a la espera de oyentes para su relato. En ese sentido, se modifica la disposición tradicional del espacio teatral, pues ya no son los personajes quienes se mueven frente a un público, sino un público que se dirige a los personajes, no para verlos actuar, sino para oírlos contar su historia. En este caso, esa experiencia es llevada al extremo, pues Garzón expone una historia muy similar en la vida de mujeres de diferentes siglos, desde el XV hasta el XX, cuando ya toda acción es eliminada y solo queda su representación en imágenes en dispositivos, pues la última mujer ya no habla, es decir, no realiza la única acción de la obra. Ella está estática en la escena, mientras en unos televisores se disponen imágenes que es lo único que se mueve. Al final ni siquiera sobrevive el discurso y la acción es una reproducción. De esta manera, la inmovilidad no solo es de los personajes, sino también de la acción que se desarrolla a lo largo de la historia hasta que se disuelve en una imagen.

La obra de Viviescas parece proponer un mayor dinamismo y aparenta una estructura dramática más tradicional y continua. No obstante, es solo una apariencia, pues el texto anuncia cada parte de la pieza como un "fragmento", es decir, como una pieza incompleta. La obra en su totalidad es la reunión de esos fragmentos que, a pesar de estar enumerados, no parecen tener un orden establecido. Cada uno de esos fragmentos expone un episodio que se relaciona con los otros por los personajes, pero que no desarrolla ninguna acción precisa. Se trata, por el contrario, de sucesos, es decir, hechos que no pueden modificar la situación que es irreconocible. Esto se debe también a la minimización de la acción, pues los personajes que aparecen en los fragmentos apenas realizan algunos movimientos, lo que hace que la situación en la que se encuentran se mantenga durante toda la obra. En esta pieza las acciones también son relatadas, lo que dificulta la identificación del drama. La inmovilidad de los personajes y la reducción de la acción, características de estas tres obras, generan una acentuación del elemento literario, pues la atención se concentra en el discurso de los personajes, que los construye, sustentado sobre una base poética y narrativa. 
El tema de las obras también las vincula. En el primer tomo de la antología, la violencia es el tema principal. En el segundo, la violencia ya no es protagónico, solo escenario. En la pieza de Cajamarca, la violencia aparece como un escenario que obliga al desplazamiento, no el de los campesinos, sino el de los integrantes de una clase media de provincia, que imaginan una mejor situación en otro territorio. La falta de oportunidades prácticas y el deseo de ascenso social que caracterizan al país es el motivo de acción de los personajes de El solar de los mangos. La obra presenta el momento final de las tres mujeres, la madre y sus dos hijas, todas en una especie de rendición de cuentas antes de la muerte. La madre retorna a su lugar de origen, con la intención de recuperar esa experiencia de comunión con el entorno que perdió al irse. Sus hijas, por su parte, están condenadas a la extranjería, pues su ambición las llevó a cometer imprudencias que resultaron en fracasos. Una de ellas es condenada en una cárcel de los Estados Unidos, la otra es víctima de una red de trata de blancas en Japón. La disposición del escenario en tres espacios diferenciados señala su relación y al mismo tiempo acentúa la lejanía en la que se encuentran una respecto a la otra. No se oyen entre ellas, aunque sus situaciones son estructuralmente las mismas. La inmovilidad de los personajes sugiere una comunicación con otro que no puede responder y que se convierte en el público, al que se apela en determinadas ocasiones como único destinatario de lo que se narra, a pesar de no ser el receptor deseado ni al que se dirigen directamente los personajes. La obra de Garzón procede de forma similar. Las mujeres de los diferentes siglos están exponiendo sus testamentos con la intención de salvarse y de resolver todos sus asuntos antes del final. Hacen partícipes de eso a los espectadores, pues se saben vistas por ellos, a quienes convierten en destinatarios de sus súplicas y de sus recuerdos. En el caso de Garzón la violencia colombiana que se representa en el conflicto armado no tiene lugar de manera directa. Al hacer un recorrido por cinco siglos, el conflicto colombiano de los últimos cincuenta años no es el único escenario, pero Garzón expone de forma tangencial la violencia en los diferentes momentos históricos del país, empezando con la conquista y colonización española. El caso de La técnica del hombre blanco parecería presentar de forma más clara el escenario del conflicto en Colombia, que se desarrolla sobre todo en el campo, pero la obra no hace referencia espacial ninguna, lo que permite una posibilidad de interpretación más amplia, así la obra no se limita solo a la violencia en Colombia, sino a la violencia humana. La técnica a la que alude el título, se refiere a las formas de actuar de Occidente, a la utilización de medios que resulten efectivos para obtener cualquier fin. Esa técnica está en relación con la civilización, tradicionalmente vista como un avance, que no se debe detener ante ningún obstáculo y que debería resultar siempre en una mejoría para la comunidad. No obstante, lo que la 
obra parece proponer es una perspectiva alterna a esa idea de civilización. El texto de Viviescas pone en escena a dos personas, una pareja, que viven en una casa de campo, tal vez se trate de campesinos que han sido afectados por la violencia. $\mathrm{O}$ es posible que sean agentes directos del conflicto, pues la descripción de los personajes dice "Korvan, apodado Roscoe. Agnes, apodada Maggy" (VIVIESCAS, 2013, p. 133), lo que significa, por un lado, que los personajes esconden su identidad; y por otro, que tal vez no tengan una, pues al alternar entre esos dos nombres aparece la dificultad de definir cuál es el nombre que los representa. Esta falta de definición impide reconocer cuál es el drama exacto de la obra. Korvan esconde en el sótano a un hombre, un posible secuestro, pero nunca se sabe quién es su prisionero ni cómo fue apresado por Korvan. Los diálogos de los personajes aluden constantemente a la cacería con perros, a la animalidad que contamina todo el espacio y por medio de la cual la oposición entre civilización y barbarie se invierte, lo que hace que el discurso, que se supone organiza y permite una comprensión tradicional de las acciones (por ejemplo la justificación de las acciones violentas y su posterior prevención), quede sustentado sobre otra base, en la que lo civilizado no son los adelantos, sino lo que se considera retrocesos. Si los aparatos técnicos son muestra de la civilización, para Korvan son la causa de la barbarie. La libertad se condena como la causa de la perdición, en oposición al cautiverio, al encierro, que sí lleva al desarrollo. De cierta forma las creencias de la civilización son revertidas en este texto, Viviescas parece decir que la violencia trastoca todos los aspectos de la humanidad y de su entorno, los vuelve al revés y hace imposible distinguir algún lugar de pertenencia, una identidad y una comunidad. En este caso, los personajes no relatan su vida para justificarse. Sin embargo, se saben parte de un conflicto que los supera, en el que cumplen un papel a veces indefinido, nunca claro, pero siempre en acción, aunque lo que aparezca en escena sea solo el relato de esta. Una de las características de esta pieza es que presenta en el discurso de los personajes un aparente conocimiento de lo que se proponen hacer, algo que no es claro para el lector, pues se les esconde o confunde. No obstante, la obra genera una atmósfera de expectativa y de tensión que aumenta con la aparición del prisionero Nirvana. Al final del texto no es posible reconocer una motivación clara en los personajes, parece ser que ellos tampoco saben con certeza para qué apresaron al hombre.

Las tres obras comentadas hasta este punto dan cuenta de un momento de detención, de duda constante que impide la acción. Que estas tres piezas presenten de forma tan clara la inmovilidad y la ausencia de acción no se debe solo a una búsqueda formal. También se debe a ciertas circunstancias de la historia que viven estos autores. El teatro es el espacio donde se presentan los conflictos de forma espectacular, es decir, para ser vistos. En un país que no necesita del teatro para ver el espectáculo, este género se dirige hacia esas 
otras formas de dar cuenta de la acción. Por eso la narración cobra especial protagonismo, pues hace falta desviar la atención de los actos para concentrarse en sus registros, en lo que dejan como resto de experiencia, como residuo mínimo de las acciones ocurridas.

El primer tomo de la antología recoge las preocupaciones de un grupo de autores, y en la que se manifiesta su compromiso con la realidad en la que se encuentran y que exige formas particulares de darle materialidad a su interpretación de esa realidad. El segundo tomo, por su parte, reúne autores que reconocen su pertenencia a un territorio en conflicto, pero un conflicto que ya se ha vuelto tradicional. Los autores más jóvenes recurren a los diferentes posicionamientos que una cultura mediática permite (formas diferentes de presentar las acciones, como las imágenes-movimiento), y hacen de la violencia y sus manifestaciones uno de los escenarios en que participan. Esto se encuentra en las tres obras que se analizarán en la segunda parte de este artículo, en la que se tomará distancia de la antología, pero se dará cuenta de las preocupaciones y propuestas que exponen los autores de esta nueva generación.

La creación colectiva y las nuevas dramaturgias frente a la violencia

Ciertamente, no se han extinguido los colectivos de creación, pero el acento en lo meramente ideológico -específicamente la preocupación didáctica- ha disminuido. Es decir, el teatro colombiano se ha abierto a un amplio abanico de temas sin abandonar la exploración del fenómeno social; no obstante, la poética que lo explora responde a una perspectiva individual. Para ver un poco cómo se da ese matiz, revisemos una de las obras de teatro colectivo más renombradas: Guadalupe años sin cuenta (TEATRO LA CANDELARIA, 2011, p. 255), catalogada como uno de los trabajos más logrados del Teatro La Candelaria.

La obra trata un evento específico: el asesinato del líder de la guerrilla campesina Guadalupe Salcedo a manos del gobierno conservador que traicionó la amnistía que había acordado con el grupo armado². A pesar de que la fábula se desarrolla conjugando distintos puntos de vista, la balanza siempre se inclina en contra del gobierno y sus tácticas pérfidas. Así, es evidente que el colectivo pretende señalar dos polos. Por un lado, el de los regentes del Estado y sus esbirros (entre los que se cuentan los soldados, simples peones del potentado) que son capaces de llegar a la mayor abyección para continuar detentando

2 La obra es resultado de una ardua investigación sobre este episodio transcurrido en 1953. El suceso es mostrado como el culmen de la deshonestidad de un gobierno que desde que inició el llamado "periodo de La violencia", en 1948, sustentó su poder en el exterminio de sus opositores. La obra se estrenó 20 años después y alcanzó 1300 funciones. 
el poder. Por otro, están los campesinos que se vieron acorralados por las paupérrimas condiciones en las que estaban (gracias a las políticas corruptas de repartición de tierras) y recurrieron a las armas, pero que renuncian a ellas confiados en la promesa de indulto y de re-inserción social. El gobierno insatisfecho, con esta voluntad de paz, asesina al comandante guerrillero y crea un montaje periodístico para desacreditarlo a él y a su movimiento.

En cuanto a la orientación ideológica, Guadalupe años sin cuenta es diáfana: su postura es de izquierda y esto se sustenta en la obra a través de las acciones en escena. De estas, la más relevante es el asesinato de Salcedo que se expone dos veces. Al inicio de la representación se muestra la versión oficial que circuló en los medios de comunicación de todo el país: "el bandolero" sale armado de su escondite compeliendo a las fuerzas armadas a "darlo de baja" en legítima defensa. Al final, el espectador es testigo de la misma escena, pero -en ese momento- ve cómo el ejército acribilla al líder que sale con las manos vacías en señal de capitulación. Esta versión es la que recogió el grupo en su investigación. Con ella da cuenta de la perspectiva de los testigos presenciales, que fueron obliterados por los medios de la época. La pieza, entonces, es contundente al dar preminencia a la versión popular.

Podemos decir que al contrario de cómo sucede en el teatro colectivo (que afronta directamente una disyuntiva clara y la resuelve en la acción escénica), los dramaturgos más jóvenes hacen una lectura lateraß ${ }^{3}$ de la realidad, que implica un cambio del acento, tanto del contenido (difícilmente se plantea una dicotomía ética), como de la forma dramática que se sustenta más en el discurso que en la acción.

Aunque se sigan tomando eventos de la cotidianidad, se abandona la idea de enterar al público de una verdad que le había sido escamoteada, para que con un nuevo conocimiento actúe frente a su entorno. De esta manera, el espectador debe centrarse en el mundo posible que crea la obra de arte, más que en el referente que la suscita. Sin el ancla de la exactitud histórica, la obra multiplica su poder de significación y el público se ve exhortado a construir un sentido según su propia lectura, no a entender el asunto expuesto.

Con el fin de ilustrar las propuestas estéticas de la dramaturgia contemporánea frente a la problemática de la violencia analizaremos tres obras: La penúltima cena, de Fabio Rubiano merecedora del Premio Nacional de dramaturgia en 1999; Coragyps sapiens, de Felipe Vergara (2011) y Hienas beben brandy, de Juan Camilo Ahumada (inédito) ${ }^{4}$.

3 Profundizaremos más adelante en este término.

4 Juan Camilo Ahumada ganó el Concurso distrital de dramaturgia de Bogotá 2013, con la obra Tiempo de Dios. La obra que se analiza aquí no ha sido publicada aunque se estrenó en mayo de 2014 . El texto escrito es una cortesía del autor. 
Fabio Rubiano 5 acuña el término lectura lateral para hablar de Mosca, una obra de su autoría que tiene como hipotexto el Tito Andrónico, de William Shakespeare, pero -que insiste- no es una adaptación:

solo está tomada la base argumental y el nombre de algunos personajes. Las relaciones entre ellos están alteradas, como también las edades, los roles y los gustos sexuales (...) Hay nuevos personajes como el Ganso avestruz, determinantes para el final de la pieza (...) En Mosca se trasmite sobre toda la obra una peste que no está en el Tito shakesperiano: por el aire, la comida, las relaciones sexuales, la sangre y la herencia genética. (RUBIANO ORJUELA, 2005, p. 9)

Como vemos, Mosca hace una relectura de Shakespeare, pero se separa de la fábula estricta de la obra para dar cabida a nuevas preocupaciones. De alguna manera, Tito Andrónico -así como los eventos violentos que suceden en la cotidianidad- lleva la semilla de una realidad humana. La intención de revisarla desde una lateralidad implica un deseo de exploración del problema desde otro ángulo. Implica el propósito de evitar la mirada cansada de una tradición que polariza cada problema y que se queda en la denuncia.

Podemos decir que la selección no es gratuita: Tito Andrónico es una de las obras más violentas del bardo, lo que la convierte en un pretexto perfecto a la hora de hablar sobre una sociedad feroz:

Mosca es una tragedia: hay un número considerable de muertos, hay hechos de violencia en cada diálogo, hay mutilaciones, violaciones, amenazas, traiciones, asesinatos, armas cortopunzantes y de fuego, venganzas, fratricidios, hasta llegar al punto en que el horror ya no produzca espanto sino risa, hasta que las atrocidades dejen, como en nuestro país, de ser un hecho extraordinario para convertirse en un hecho ordinario. La cuchillada y el disparo son importantes en la obra, pero insistir en ellos era desaprovechar la posibilidad de profundizar en las causas (...) Así que desde la construcción dramática del texto hasta la puesta se decidió no poner en escena una sola gota de sangre, hacer énfasis en las demás relaciones y tratar de generar el horror por medio de la palabra. (RUBIANO ORJUELA, 2005, p. 9)

Así que, si bien Rubiano tiene clara la temática ("es una tragedia"), también tiene claro el público al que se dirige ("nuestro país"). En otras palabras, el autor interpela a una sociedad que posee una conciencia embotada, casi imposibilitada para distinguir "lo ordinario" de "lo extraordinario". De una parte, se niega a repetir el gesto violento que la sangre evoca. $\mathrm{Al}$ autor no le interesa quedarse en lo visceral, pretende ir más allá, ir hasta la causa

5 Fabio Rubiano establece la relación entre Mosca y Tito Andrónico mediante este concepto en el programa de televisión Estaciones del drama (RUBIANO, 2008). 
y la exploración de las relaciones. De otra parte, no recurre a los sucesos cotidianos, porque es consciente de que, a pesar de que "la realidad cercana es un referente innegable no solo en esta pieza, sino de cualquiera que se escriba en estos tiempos (...) [es necesario crear] distancias con los lenguajes, el tono y la estructura para no generar analogías ni alegorías" (RUBIANO ORJUELA, 2005, p. 10).

Así que si el autor no apela a la realidad misma (a sabiendas de que es innegable como referente), ni a la analogía, ni a la alegoría, podemos decir que su búsqueda no pretende que el espectador apele directamente a la historia patria, pero, gracias a esa plétora de menciones de los hechos violentos, la realidad nacional será traída a la memoria como eco o como fantasma. Podemos decir que sucede lo mismo con la tragedia del inglés: aún deformada o transmutada sigue estando presente; la relación con una y con otra -la realidad y la tragedia- será percibida lateralmente.

Teniendo en cuenta la tradición de la violencia como tema del arte colombiano, es fácil constatar que es usual que haya una denuncia en contra del agresor y una reivindicación de las víctimas, como en la obra citada del Teatro la Candelaria ${ }^{6}$. Sin embargo, Rubiano abandona esta postura dicotómica. En primer lugar, se niega a tomar partido por unos u otros. Su obra se basa en las relaciones confusas que se trazan entre personajes de moralidad ambigua. De hecho, los personajes que podrían entenderse como víctimas siempre tienen particularidades que los acercan a lo repudiable: son traidores, lujuriosos, vengativos o -tal vez- simplemente estúpidos. No ocurre siempre así con los victimarios, no siempre se atenúa su carácter despótico o cruel con peculiaridades benéficas. Esta inclinación a considerar que los seres humanos tenemos, en general, una tendencia hacia la perversión da cuenta de una crítica profunda de la sociedad ${ }^{7}$. Ahora, lo que sí es usual es que sus obras se centren en personajes reconocidos porque tienen una tacha moral.

Justamente eso es lo que pasa en La penúltima cena, que se centra en los diálogos - hay un detrimento de la acción por la palabra- entre Judas

6 En Estado del arte dramático en Bogotá, los autores afirman que la línea temática sobre la política ha disminuido, para dar paso a la preocupación a las obras con sustrato en el tema de la violencia (PULECIO MARIÑO, ALFONSO PENA, \& PARDO, 2007, p. 132). Obras como La maestra, de Enrique Buenaventura; Gallina y el otro o Donde se descomponen las colas de los burros, de Carolina Vivas plantean una reivindicación de las víctimas de la violencia, particularmente de la que se vive en las zonas rurales y afecta directamente a los campesinos. Este enfoque reporta un valioso aporte en cuanto a restitución de la memoria. De alguna forma su función social es mantener presente el conflicto para que el espectador sienta que la pérdida de cualquier ciudadano es una pérdida absurda, aun cuando no sea la de un miembro de su familia.

7 Esto es claro en Cada vez que ladran los perros. Una obra en la que los perros sufren una peste: se convierten en hombres y mujeres; en la transformación adquieren las peores cualidades de la especie humana. Entre más avanza el proceso son capaces de cometer atrocidades más y más sofisticadas sin ningún objetivo específico más allá del regocijo que les produce el dolor ajeno. 
Iscariote y María Magdalena. La obra se sitúa la noche antes de la despedida y captura del redentor. Judas espera tener -él también- un ágape en el que se reconozca su papel fundamental dentro de la trama bíblica. Al mismo tiempo, espera que el rito de la cena alivie el dolor de la culpa. Necesita ser reconfortado y resarcido previamente por la traición que se dispone a cometer. Sin embargo, Judas no es solo el discípulo felón, ni María es solo una seguidora (posiblemente enamorada) que ha sido reformada por Jesús. Los dos personajes devienen múltiples: podríamos decir que su cuerpo individual encarna distintas ontologías que se yuxtaponen. Por un lado, son los acompañantes de Jesús. Por otro, son actores que esperan representar la crucifixión en una puesta en escena. También, son personas con historias cruzadas: él, un zelote que lucha contra el imperio romano y ella, una prostituta barata que alguna vez le prestó sus servicios. Pero, además, ella es una mujer actual que sufre un duelo y se ve obligada a ir a un depósito de cadáveres para descubrir que no está el cuerpo que ella busca. Del mismo modo, Judas es miembro de un grupo guerrillero que pone una bomba en una embajada, como forma de venganza política. Además de que cada uno vive vidas distintas, que se traslapan haciendo invisibles los límites entre una y otra, hay un momento en el que cambian de ropas y al hacer el trueque intercambian sus historias; únicamente así llegan a contar su intimidad más secreta.

Todas estas ontologías parciales se superponen en un juego de simultaneidades que desconciertan al lector, pero que también le permiten una mirada amplia -o, mejor, profunda-sobre cada uno de los personajes. Rubiano juega a esbozar al personaje como una construcción de múltiples relatos, lo que implica una crítica a la idea de la identidad única: esa multiplicidad revela que María y Judas son artificios, creaturas tejidas con diversos hilos. No obstante, esa intertextualidad (pues son textos diversos que se tejen) permite que uno y otro sean muy humanos: ambos sienten miedo y rabia, ambos sufren, ambos se deleitan escatológicamente en el placer, los dos han amado y los dos están condenados a ser una cifra estadística más. El dramaturgo -esto sucede en toda la obra de Rubiano- recurre a los personajes secundarios de la historia, de la cultura, de la literatura y los transforma, mediante la ironía, la hipérbole, el humor cruel para demostrar la inconsistencia del discurso moral. No hay buenos ni malos: las víctimas, tanto como los agresores, van más allá de su papel y se descubre que la dicotomía moral sobre la que se ha montado toda nuestra cultura tiene resquebrajaduras que obvian la complejidad de lo humano. Así, todo encomio de la bondad humana es falso, como es falso todo repudio de lo deleznable.

Y aunque el dramaturgo no tome partido ideológico evidente, no deja de tocar, lateralmente, el contexto concreto. La referencia al conflicto armado colombiano puede parecer velada; no obstante, en el país es imposible hablar de masacres, o de explosiones sin que de inmediato haya una resonancia con 
el conflicto interno. De este modo, se puede percibir la crítica y el dolor frente a la problemática nacional, no obstante esta se halla enmarcada en un plano mucho más general. Así como en Mosca, la violencia literaria y la real se acoplan, en La penúltima cena la alusión a las víctimas mezcla a los santos bíblicos con los colombianos -sin detenerse a discriminar entre buenos y malos- asesinados. Así, cuando María se empeña en encontrar el cadáver insepulto de Jesús, sin esperanza de resurrección, va con Iscariote al depósito de cadáveres y este hace un inventario de mártires bíblicos y luego afirma:

Los despojos inmortales del protagonista no están aquí (...)

Judas: Hasta aquí llegan los mártires, los héroes, las santas, los santos... de aquí para allá es la basura:

(Señala al otro extremo).

Los treinta y ocho de aquella esquina fueron torturados con sus esposas y sus hijos en venganza por los anteriores, aquel que aún tiene los zancos amarrados a los pies era el saltimbanqui de Sahagún, le sacaron los ojos y le cortaron los dedos, cuatro líderes que nadie se atreve a defender, nueve familias calcinadas con sus perros...

(Mira con detenimiento).

El resto son anónimos, irreconocibles o solitarios que nadie reclama. No veo a Jesús. (RUBIANO ORJUELA, 2005, p. 42-43)

Por otro lado, Felipe Vergara tiene una estrategia distinta al acercarse al tema de la violencia colombiana. En algunas de sus obras hay una intención de recapitulación y reflexión acerca un hecho histórico preciso. Sin embargo, no es la denuncia lo que busca. El hecho, generalmente, está traspasado por un simbolismo que complejiza la interpretación. En Coragyps sapiens (2013, p. 181) nos encontramos con una pieza que no solo se sustenta en la palabra (como se mencionó que sucede constantemente en la dramaturgia actual), sino que se solaza en ella. El texto es profundamente literario en el sentido de que logra transformar un hacinamiento de cuerpos en descomposición, con toda su materialidad grotesca, en algo que se puede concebir como elemento de belleza. Desde la primera acotación, nos encontramos con un protagonista que alimenta buitres con restos de seres humanos que perecieron violentamente y se agolpan en el río como escoria que a nadie le concierne:

$\mathrm{Al}$ encenderse la luz, solo se ve una serie de gallinazos que circulan en el aire. Abajo Ulpiano se mece en una mecedora mirando hacia arriba. Tan pronto aparece el rey de los gallinazos, una espléndida ave blanca, Ulpiano desata una cuerda que hace descender sobre el escenario una balsa con flores y velas. Una olla de aluminio llena de hollín, de donde emerge una fuente de tripas de todos colores, reposa en el centro de la balsa. El rey de los gallinazos desciende y picotea lo que hay en la olla. (VERGARA, 2013, p. 181) 
Poco a poco nos vamos enterando de que los cuerpos no tienen identificación, de que no se sabe si son culpables o víctimas. Lo único cierto es que todos perecieron por la violencia. Es decir que este autor, como Rubiano, desecha la polarización moralista. Pero no lo hace solo al negarse a tomar un partido claro por víctimas o victimarios, sino que, a través de un lenguaje que constantemente se desliza hacia lo poético, hace un traslado de lo meramente grotesco a lo simbólico. Así, la presencia de "una balsa con flores y velas" (VERGARA, 2013, p. 181) en la que se posa "Una olla de aluminio llena de hollín, de donde emerge una fuente de tripas de todos colores" (VERGARA, 2013 , p. 181) nos trae a la mente un ceremonial religioso. Se trata de un ara ritual en la que se ofrendan alimentos del cuerpo y el espíritu. Ulpiano y Reina (únicos personajes) entienden al buitre como un ser casi divino, con la capacidad de elevar a los muertos hacia el cielo. Los gallinazos se alimentan de un cadáver y después vuelan, pero este acto natural es metaforizado y se convierte en un viaje trascendental en el que el ave transporta el espíritu. Nunca hay referencia a un más allá, solo sabemos que hay una liberación, un estado mejor, que puede ser la Nada.

Aquí de lo que se trata es de una reflexión sobre el ser humano, al que se le compara con el buitre. El autor retoma tradiciones indígenas y populares latinoamericanas que consideran al buitre como un hierofante para mostrar la supremacía de un animal que es capaz de convertir la muerte en vida, en oposición a lo que hace el ser humano. En taxonomía, el buitre es parte del género coragyps que lo define como un ave carroñera. Eso quiere decir que no mata, que no es un asesino. Además, los buitres acostumbran a notificar a otros cada vez que hacen un hallazgo de cadáveres para compartirlos, siguiendo un comportamiento en el que cada uno cumple un papel dentro de su comunidad. Pero lo más relevante es que cada difunto recobra el sentido que le fue hurtado al ser asesinado: se convierte en alimento para la próxima generación, se convierte en vida.

La propuesta que sugiere Vergara es que cada uno de nosotros puede ser partícipe de esa elaboración de la muerte:

Haga como los chulos. Ellos comparten su comida, comparta usted la suya (...) Deme uno, Ulpiano, mire que yo lo necesito de verdad. Le juro que yo le ayudo, Ulpiano. Lo digiero de alguna manera, lo regurgito si es necesario, me lo vuelvo a tragar y lo convierto en vida. Algo hay que hacer con ellos. (A alguien en el público.) Llévese uno. Es obvio que vino a eso. (VERGARA, 2013, p. 203)

Es posible elucubrar que esta sea una nueva vía para sanar parte del dolor que entraña el combate armado que no cesa. Cada persona -desde lo cotidiano-adopta una víctima, le pone un nombre, le inventa una historia, 
lo reconoce como un ser humano, sin importar a cuál bando perteneció en vida. Lo esencial en la obra de Vergara es el reconocimiento del otro como parte de la familia, es decir, como alguien por quien se sufre un duelo. Y el duelo debe redundar en una conciencia, en una sensibilidad, en una nueva forma de ver la vida.

Por su parte, la dramaturgia de Juan Camilo Ahumada es mucho menos esperanzadora. Si Felipe Vergara termina el texto señalando una responsabilidad individual que influiría positivamente en un proceso doloroso como el de la violencia colombiana, Ahumada nos presenta, en Hienas beben brandy, un tiempo post apocalíptico en el que el hombre es la hiena del hombre (parafraseando a Thomas Hobbes). Y, aunque su obra no especifica un tiempo ni un lugar preciso, se puede inferir que habla de la sociedad actual y específicamente de la colombiana por algunas alusiones semi-veladas.

El argumento se sitúa después de la guerra y hay pocos sobrevivientes, la extinción los amenaza, pues no hay fuentes de agua y la poca que queda está contaminada con mercurio. Quedan cuatro hombres ${ }^{8}$ que forman una familia de cazadores, de asesinos que se dedican a ejecutar inmisericordemente a las mujeres que no fenecieron a causa de una plaga que acabó con la mayor parte del género. Se deduce que ellos son jóvenes, violentos, llenos de prejuicios y el odio acerbo hacia todo lo ajeno se incrementa en las condiciones de precariedad en las que viven; a pesar de que están en un mundo en el que no hay nada que salvar (se saben condenados a la muerte por asfixia y hambre, o por la mano de uno de sus hermanos), se enorgullecen de su supuesto rol de preservadores:

Estamos salvando a la tierra de su destrucción. Me tranquiliza saber que el aire que respiro es cada vez más puro. Que estamos llegando a nuestro punto más alto. Que hago parte de la generación de humanos más evolucionada de toda la historia de la humanidad. Me tranquiliza también saber que puedo ser el último habitante de la tierra. Que la despoblamos. Que con la muerte de la reproductora matamos la reproducción y con ella aseguramos el futuro. (AHUMADA, 2014, p. 13)

El resultado no va a ser otro que el exterminio de la especie, pero, quizá, sólo en un mundo despoblado de humanos, la tierra pueda tener un porvenir.

Las mujeres, por su parte, se encuentran reducidas al ostracismo. Estos personajes presentan una particularidad, y es que funcionan no sólo como personajes singulares, sino que abarcan su género. Es decir, los cuatro hombres se identifican como individuos: cada uno tiene un nombre, de cada uno puede intuirse una cierta personalidad. En cambio, en ellas no se determina

8 Breda, Conín, Grepo y Ancús. 
una individualidad clara, sus nombres son los pronombres deformados y el nombre del género: Laa, Ela y Mujer. Este rol tripartita emerge como la madre: la mujer que pare y pierde hijos en la guerra. Las tres constituyen un personaje coral, por así decirlo, que encarna el arquetipo de la mujer que sufre el duelo de la violencia una y otra vez:

Apiádate señor de una madre que nunca más vio a su hijo y que lo imagina desmembrado, mutilado, convertido en carrońa para aves. ¡Mírame a los ojos, señor! ¿'También a mí me abandonas como abandonaste la pobre alma silenciosa del hombre que aquí lloro? ¿'Te burlas de mí?

Te burlas de esta pobre madre que tuvo que parir.

Yo tuve un hijo y frente a tus ojos lo acuchillaron.

Yo parí un hermoso bebé que cayó baleado en una esquina.

De mí salió un hombre que fue quemado vivo.

Yo traje a la vida a un niño que estalló en pedazos.

¡Quiero secarme por dentro! (AHUMADA, 2014, p. 16)

Vemos cómo la Mujer le reclama a Dios por el niño-hombre que ha sido ejecutado de diversas maneras. En otras palabras, se hace presente toda violencia contra el hombre, sin distinguir niveles de inocencia o de culpabilidad. Esa madre que clama con patetismo en esta ocasión, sueña con herir a su hipotético hijo, lacerarle los pies para que no se aleje de ella y permanezca bajo su cuidado como única medida para impedir que se convierta en un adulto que hiere o que será herido. También, se dibuja en -otro momento- como una mujer capaz de enfrentarse y escupir en la cara de sus captores antes de su seguro homicidio (AHUMADA, 2014, p. 32). Asimismo, los personajes masculinos tienen una identidad oscilante. Aunque la mayor parte del tiempo son brutales, todos tienen momentos de fragilidad, de debilidad y de contrición por los crímenes que han cometido.

Hienas beben brandy (AHUMADA, 2014) es una obra que, si bien habla de un futuro que podríamos llamar póstumo, habla lateralmente del presente. No hay duda, de que el conflicto social y político ha calado en la obra. Como decíamos antes, los personajes son jóvenes y el mundo en el que crecieron ya había sido arruinado por la violencia aun antes de la última guerra. Su infancia (Breda, el menor, es apenas un adolescente) transcurrió alejada de los adultos; no tuvieron guía más que la depredación de la que fueron testigos.

Conín: Cuando era niño me entretenía mirando a mamá maquillarse frente al espejo (...) ¿Cuántos años tendría cuando yo nací?

Breda: ¿Cuántos años cuando la matamos?

Conín: ¿La matamos? 
Breda: La maté, la mataste, la mataron, la matamos. (...)

Breda: Trata de recordar el cuerpo de tu madre golpeado, aun con cabeza, tirado en el piso, tirado en la arena amarilla, salpicado de barro, de barro de greda, la cara manchada con una máscara de barro, recuerda a tu madre muriendo y recuerda tus lágrimas. (Conín paró de reír) Esa vez fue la última que lloraste. (AHUMADA, 2014, p. 8-10)

Para los colombianos no es lejana esta idea de crecer en medio de la violencia. Desde la Conquista, la historia del país se ha dado entre muertos y sangre, con pocos momentos de relativa tranquilidad. Pero la violencia partidista que se inició en 1948 no se ha detenido y, a lo sumo, solo fluctúa en intensidad. Llevamos 67 años de conflicto armado, lo que quiere decir que apenas viven colombianos que hayan conocido un remanso de paz nacional. Nosotros, como los personajes de Ahumada, nacimos en un mundo donde la ley la fraguan la violencia y la ambigua moralidad actual. El discurso que habla del bienestar del humano y del cuidado del planeta, pero que al mismo tiempo pretende el poder a costa de cualquiera, sin importar el daño que se cause al otro y al medio ambiente. Así, los personajes masculinos se enorgullecen de su labor de exterminio, no obstante la pena que sienten por la pérdida de seres amados o la culpa que sienten por los homicidios que han cometido. Aman a sus hermanos y no ven ninguna contradicción en la certeza de que en cualquier momento pueden sucumbir o hacerlos sucumbir por mano propia.

La ambigüedad también habita en la mujer arquetípica que no es sólo la madre doliente de una víctima, es doliente porque también es la que pare al hijo asesino. La reproductora del hombre es, simultáneamente, víctima, madre de la víctima y del victimario. Sin embargo, no es el ser lleno de bondad con el que se identifica tradicionalmente ese arquetipo. Esta madre está decidida a usar una violencia que raya en la brutalidad en contra de su propio hijo. Su finalidad es noble: evitarle cualquier terrible destino, pero el método es irracional e iracundo.

Si hasta ahora puede darse la impresión de que en la obra se presenta una lucha entre géneros, se puede decir que el dramaturgo la borra con un gesto continuo en el que los personajes masculinos se travisten. Este gesto es ambiguo porque amalgama el odio y la admiración por lo femenino. La ambivalencia ética de los personajes parte de esa difusa y equívoca época en la que los valores se han desacralizado.

Como es evidente, Juan Camilo Ahumada no celebra el abandono de esos valores, parece más un testigo del derrumbe. No hay conciliación posible ni con el lenguaje ni con el otro, como en Coragyps sapiens, pero sí hay una construcción de la obra de arte desde las pavesas de mundos distintos que se interrelacionan. Por eso, como en la obra de Rubiano, hay una alta 
intertextualidad con la literatura, con la historia, la biblia y, sobre todo, con la cultura popular actual'?.

Si las tres obras comparten la mirada lateral, es porque tienen una voluntad de expresarse distinto, lo que se lleva a cabo en la disección de la forma tradicional del teatro. Por un lado, recurren a la palabra más que a la acción; por otro, especialmente en Rubiano y en Ahumada, la forma dramática pierde linealidad, con lo que se destruye la progresión cronológica. En las tres dramaturgias, la anécdota transcurre en un tiempo indeterminado y en un espacio impreciso, lo que redunda en que el personaje y su palabra se constituyen como eje de la pieza dramática.

No es vana la idea de que la forma dramática ha perdido la cohesión que antańo se había privilegiado. Las piezas contemporáneas privilegian una cierta dispersión de temas, de técnicas y de formas de enunciación porque hay una honda necesidad de hablar del mismo problema en nuevos términos. La integración de otros lenguajes ha enriquecido el cómo contar una Historia que se repite generación tras generación sin tregua, pero que cada día penetra más en la cotidianidad de los colombianos. De esta forma, el teatro actual va más allá de la denuncia, abandona el papel didáctico, propiciando un terreno de reflexión complejo, que parte de lo estético y que apela al lector-espectador como copartícipe en la creación de sentidos.

Es necesario mencionar nuevamente que el teatro colombiano presenta un amplio abanico de posibilidades. La diversidad de temas y de estilos que conviven es parte de un rico acopio de agrupaciones y autores que han logrado ser reconocidos. Entre las dramaturgas jóvenes son de obligatoria mención Martha Márquez, Verónica Ochoa y Victoria Valencia. Entre los grupos con trayectoria debemos nombrar a: Vendimia teatro (Carlos Araque) que se define como una agrupación interdisciplinar con énfasis en lo antropológico; Teatro Varasanta (Fernando Montes), Teatro Quimera (Fernando Ospina y Jorge Prada), Teatro Libre (Ricardo Camacho) y Colectivo Teatral Matacandelas (Cristóbal Peláez) cuyo interés se centra en la relación entre la tradición y la creación contemporánea. Teatro de Occidente (Carlos Sepúlveda) y Mapa Teatro (Heidi y Rolf Abderhalden) que se ubican en la línea de creación en las artes vivas. La navaja de Okham (Catalina Moskowitz) y Teatro R101 (Hernando Parra) que tienen interés en la interdisciplinariedad artística.

\footnotetext{
9 Para dar un ejemplo: la mayor parte de los nombres de los fragmentos en los que está dividida la obra permiten ilustrar esto: 2. ERES UN OBJETO DE ESPANTO Y HAS DESAPARECIDO PARA SIEMPRE (Ezequiel 28: 12-19); 3. QUE LA MANO DERECHA NO SEPA LO QUE HACE LA IZQUIERDA (Mateo 6:3); 4. JESÚS; 5. ESTA NOCHE QUIERO BRANDY (canción del género balada romántica interpretada por Django); 7. ASHES TO ASHES (canción de David Bowie); 9. MADRE, HE AQUÍ A TU HIJO, paráfrasis de la tercera palabra de Jesús en la cruz: "Mujer, he aquí tu hijo; Juan he ahí tu madre" (Juan 19:26-27); 11. YO TUVE QUE MATAR A UN SER QUE QUISE AMAR (fragmento de la canción La cárcel de Sing Sing, de Alci Acosta) y 14. NE ME QUITTE PAS (canción de Jacques Brel).
} 
AHUMADA, Juan Camilo. Hienas beben brandy. Bogotá, 2014.

CAJAMARCA, Orlando. El solar de los mangos. In: LAMUS, M. Dramaturgia colombiana contemporánea. Bogotá: Ministerio de Cultura, 2013.

GARCÍA-BARRIENTOS, José Luis. Cómo se comenta una obra de teatro: ensayo de método. Madrid: Editorial Paso de Gato, 2012.

GARZÓN, José Domingo. La procesión va por dentro. In: LAMUS, M. Dramaturgia colombiana contemporánea. Bogotá: Ministerio de Cultura, 2013.

MINISTERIO DE CULTURA DE COLOMBIA. Plan Nacional de Teatro: Escenarios para la vida 2011-2015. Bogotá: Ministerio de Cultura, 2011.

PULECIO MARIÑO, Enrique, ALFONSO PEÑA, Miguel \& PARDO, José. Estado del arte del área de arte dramático en Bogotá D.C. Bogotá: Alcaldía Mayor de Bogotá, 2007.

RUBIANO ORJUELA, Fabio. La penúltima cena. Medellín: Universidad de Antioquia, 2005.

RUBIANO ORJUELA, Fabio. El teatro de hoy: espejo de un hombre roto. Estaciones del drama. Obtenido de <http://www.prismatv.unal.edu.co/nc/detalle-serie/ detalle-programa/article/el-teatro-hoy-espejo-de-un-hombre-roto.html>. 2008.

TEATRO LA CANDELARIA. Guadalupe años sin cuenta. In: Teatro la Candelaria: 45 años. Bogotá: Ministerio de Cultura de Colombia, 2011.

VERGARA, Felipe. Coragyps sapiens. In: LAMUS, M. Dramaturgia colombiana contemporánea. Bogotá: Ministerio de Cultura de Colombia, 2013.

VIVIESCAS, Víctor. La técnica del hombre blanco. In: M. LAMUS. Dramaturgia colombiana contemporánea. Bogotá: Ministerio de Cultura. 2013. 
Alexandra Aguirre Rojas. Profesional en Estudios Literarios de la Universidad Nacional de Colombia. En la misma universidad, es aspirante al título de Magíster en Estudios Literarios con la tesis La disolución del personaje en la dramaturgia de Fabio Rubiano. Ha sido docente de poéticas teatrales (colombiana, latinoamericana, vanguardia, clásica) y de cursos sobre arte e interdisciplinariedad en la Facultad de Bellas Artes de la Universidad Pedagógica Nacional. Actualmente lleva a cabo una investigación sobre el teatro contemporáneo colombiano. E-mail: alhadexandra@gmail.com

Mario Henao. Profesional en Estudios Literarios de la Universidad Nacional de Colombia. Realiza en estos momentos su tesis de maestría en Estudios de Cine y Teatro Argentino y Latinoamericano en la Universidad de Buenos Aires. El tema de su tesis es la dramaturgia del escritor franco-argentino Copi. Ha trabajado como profesor de colegio y de universidades en donde ha estado a cargo de cátedras sobre el oficio de escribir. Publicó artículos sobre cine, entre los que se destaca el realizado sobre la película del mexicano Arturo Ripstein El lugar sin límites. Este artículo salió en la revista de la Asociación Argentina de Estudios de Cine y Audiovisual. Ha participado en diferentes coloquios y congresos sobre teatro. Además, participó como actor en la obra documental Mi única fe, presentada en Buenos Aires, en el Festival Fringe 2013 de Madrid y en la Bienal de Arte Joven de Buenos Aires 2013. En compañía de Nicolás Morales fundaron el club del Fuego Secreto en la librería Casa Tomada en donde desarrollan charlas sobre literatura queer. E-mail: mariofhenao@gmail.com 